\title{
DOUTRINA
}

\section{Conceito e Propriedade das Nascentes}

JAIR TOVAR

\section{I - NASCENTE E FONTE}

A expressão "nascentes" tem tido em nosso direito, em paralela atuação com o direito português, compreensão idêntica à da expressão "fonte", confundindo-se numa só idéia ơ que uma e outra procuram objetivar. (1)

Assim é que Alves Moreira (2) e no mesmo pensamento expositores patrícios, (3) quando fixam o conceito de uma, conjuntamente agregam o entendimento da outra.

Dessa influência não fugiu o Código Civil, pois no, artigo 565, fala exclusivamente do vocábulo "fonte", (4) para exprimir exatamente aquilo que o Código de Águas regula sob a denominação de "nascentes".

$\mathrm{E}$ os seus comentadores conspícuos, usam ora de uma expressão ora de cutra, como cativas a um só conceito. (5)

$\because$ Todavia, desde a Resolução Régia de 17 de agôsto de 1775 (6) já se insinuava, mesmo no nosso direito, distinção para elas, conforme hoje a reconhecem várias legislações e a cultura jurídica em geral.

TEIXEIRA DE Freitas consolidou êsse processo de distinção, utilizando, no artigo 901 de sua tradicional codificação, a expressão "nascente" com o sentido específico, que a distingue da expressão "fonte", (7) anteriormente usada em sentido geral.

Não obstante tal distinção se ter tornado efetiva, o Código de Águas, no artigo 89, voltou a considerar as duas expressões para os efeitos, de suas disposições, como depositárias de conceito idêntico, nos seguintes têrmos: "consideram-se "nascentes", para os efeitos dêste Código, as águas que surgem naturalmente, ou por indústria humana e correm dentro de um só prédio particular e ainda que o transponham, quando elas não tenham sido abandonadas pelo proprietário do mesmo".

Conquanto na terminologia jurídica tenham o tratamento de sinônimas, as duas expressões, etimològicamente, têm significado diverso. (8)

Por "nascente" entende-se o lugar onde a água brota espontâneamente, enquanto que a palavra "fonte" designa o local adaptado pelo homem para recolhimento ou captação das águas, o qual pode ser, ou não, aquêle onde elas brotam da terra. (9) 
Rossel e MEntha dão a seguinte definição ao que se deva entender por "fonte" em face do Código Suíço: "s'entend de l'eau qui apparaît, d'une manière durable, à la surface du sol, qu'elle en jaillisse naturellement ou qu'elle ait été artificiellement capté". (10)

Já no atinente ao conceito de "fonte", o velho LoBÃo, referindo-se a BoBADILla, dava uma notícia em que se vislumbra a colaboração do trabalho humano para sua compreensão.

Assim dizia: "A abundância da água é uma das coisas mais necessárias para as cidades e povos de quantas são precisas na República; e assim PlAtão em suas leis encomenda aos edis que procurem ter copiosas e claras fontes, que não só sirvam aos vizinhos, mas que juntamente adornem a cidade. O mesmo advertiu ARISTóteles". (11)

E acrescentava que "o reparo das fontes é mais importante que o reparo dos caminhos".

Carvalho DE Mendonça define "nascente", incluindo a "fonte" em seu conceito, como "qualquer jacto de água que brote da terra, natural ou artificialmente". (12)

\section{II - PREFERÊNCIA DA EXPRESSÃO "NASCENTES"}

Dizendo que se consideram "nascentes" as águas que surgem naturalmente ou por indústria humana, o Código de Águas fixou de modo implícito a distinção entre "fonte" e "nascente", atribuindo a esta um caráter genérico e limitando àquela uma compreensão específica.

Essa foi a preferência perfïlhada por VALADÃo, que a justificava da seguinte forma: "E para o que eu tinha em vista, parece-me, mais se prestava, por mais ampla, a expressão "nascentes" do que "fontes". De fato: na linguagem ordinária e no uso comum as palavras fonte e nascente não significam exatamente o mesmo pensamento, porque a fonte pressupõe algum trabalho para o aproveitamento das águas, e nas nascentes a água brota naturalmente do solo". (1)

VARCASIA, na nomenclatura com que finaliza seu estudo especializado sôbre as águas, assinala que a palavra "fonte" compreende as águas não só das fontes naturais - ou sejam aquelas que por si brotam da terra, como também aquelas que foram trabalhadas ou escavadas pela mão do homem. (2)

Parafraseando-se o que Columela disse, ao cotejar as expressões "fonte" e "poço", (3) poder-se-ia dizer, diante da sistemática do Código de Águas, que tôda fonte é nascente, mas nem tôda nascente é fonte.

THEMistocles CavalCANTI encontra para a "nascente", pelo aspecto técnico, um sentido restrito, compreendendo apenas aquelas águas que não transpõem os limites de um prédio, abandonadas pelo seu proprietário; e se tal acontece, outras dencminações lhe devem ser atribuídas."

Daí reconhecer-lhes o domínio particular.

Todavia, tal conceito se choca com o disposto na parte final do artigo 90 do Código de Águas. (5) 


\section{III - DISTINÇÃO DAS NASCENTES}

As "nascentes", considerada essa expressão em sentido genérico, podem ser naturais ou artificiais, consistindo-se as últimas fontes abertas (poços) e de fontes fechadas (denominadas "artesianas").

As fontes abertas ou poços são feitos em terrenos escavados, em maior ou menor profundidade, até ser atingido o veio hídrico subterrâneo e do qual brota a água na superfície.

Cumpre distinguir aqui a nomenclatura que o direito italiano faz, no atinente aos "reservatórios" de águas, que podem ser construídos não só para as águas pluviais como também para as nascentes, sejam elas naturais, ou artificiais, destinados à distribuição de àgua pelos canais de irrigação, daqueles outros resultantes de escavações, mais ou menos profundas, realizadas no terreno, para obtenção de águas para usos dơmésticos e ainda também dos destinados ao recolhimento e conservação das águas pluviais para os mesmos usos.

Os primeiros são designados pela expressão "serbatoi"; e os segundos e terceiros, pelos vocábulos "pozzos" e "cisternas".

Outrossim, faz-se conveniente a fixação da diferença, que existe, dados os efeitos de uma e outra, entre "nascente" e "corrente".

CARVAlHo DE MENDONÇA estabelece o conceito de ambas da seguinte forma: "Corrente se diz a água que passa de um lugar a outro conforme uma direção regular e determinada. Nascente é qualquer jacto de água que brota da terra, natural ou artificialmente". (3)

Ao estudar o problema, por ocasião de elaborar o seu Projeto de Código de Águas, VALADÃo distinguiu as águas nascentes como sendo aquelas que brotam ou surgem dentro de um prédio particular, ou ainda que o transponham, sem que pelo proprietário do prédio tenham sido abandonadas; e águas correntes, quando abandonadas correm pelos prédios inferiores.

\section{IV - ORIGENS E DETERMINAÇÃO DAS NASCENTES}

As nascentes, como observa CARVALho dE MENDONÇA, em magnífica lição a respeito, não têm uma origem única, contribuindo para sua formação "a precipitação dos vapores atmosféricos, a fusão das neves, a infiltração das chuvas e a do mar, a ação capilar do solo, o levantamento dos vapores subterrâneos, a ação do pêso que arrasta os líquidos até as camadas inferiores da terra". (1)

Da infiltração da água e do grau de permissibilidade das camadas geológicas, especialmente, resulta o processo de formação das nascentes.

Para essa infiltração tem-se admitidơ a contribuição até do mar, não só através da evaporação e posterior precipitação como também até pela infiltração, segundo admite DESCARTES explicada a perda dos elementos salinos pela decantação, neste caso, e pelo respectivo depósito, naquela hipótese.

Abstraindo a origem das nascentes, o Código de Águas, entretanto, determina-lhes o ponto, em que adquirem consideração, como sendo aquêle onde 
as águas começam a correr pelo solo e não pela veia subterrânea, que as alimenta. (2)

Tôda a nascente é, indubitàvelmente, consequiência de uma veia subterrânea, que a alimenta.

Essa veia, porém, é elemento, que merece da lei certa consideração para efeitos jurídicos à parte, e não se integra no seu conceito.

No capítulo referente às "águas subterrâneas", estão os preceitos que regulam a espécie, havendo incidência direta delas na matéria em estudo, quando se proíbe, expressamente, ao proprietário do solo, sob o qual elas fluam, construções capazes de poluir ou inutilizar, para uso ordinário, a água do poço ou da nascente. (3)

\section{V — PROPRIEDADE DAS NASCENTES}

A propriedade das nascentes é em princípio particular, pertencendo aos prédios onde águas surdam à superfície.

Nosso direito consagra êsse princípio desde quando a comentada Resolução de 17 de agôsto de 1775 assim o reconheceu explìcitamente: "Hei por bem declarar que o domínio e posse das águas de que se trata, sendo estas, como são particulares, pertencentes aos donos das quintas onde têm seus nascimentos," etc.

Já no velho direito português, que nos foi legado, não se fazia dúvida acêrca dêsse reconhecimento, conforme se vê em várias passagens constantes de Lobão, (1) Borges Carneiro, (2) e Corrêa Teles; (3) e discrepância não houve na atitude posterior do nosso direito já autônomo, pois TEIXEIRA DE FREITAS estabeleceu na sua Consolidação o reconhecimento do princípio nos seguintes têrmos: "O domínio e posse das águas, quando são particulares, pertencem aos donos dos prédios onde têm elas seus nascimentos." (4)

Com igual firmeza LAFAYETTE endossou: "O domínio e a posse das águas particulares pertencem ao dono do prédio em que nascem". (5)

VALADÃo respeitou o direito consagrado pela doutrina, fazendo-o outrossim decorrente de vários textos, para consolidar o conceito da plena propriedade particular das águas nascentes. (6)

De igual forma sucede com o direito de outros povos, onde vamos haurir subsídios para o nosso pois que tal era oriundo do próprio direito romano. (7)

Em Portugal, a tradição foi conservada e o seu Código Civil o reconhece de modo explícito no art. 444: "O dono do prédio, onde houver alguma fonte ou nascente de água, pode servir-se dela e dispor do seu uso livremente, salvo o direito que algum terceiro tenha adquirido a êsse uso por justo título". (8)

Na Itália, (9) na França (10) e em geral nos países do direito ocidental (11) prevalece a mesma reserva da propriedade das águas em favor dos donos dos terrenos onde elas nascem, sem embargo das limitações e peculiaridades inerentes às respectivas legislações. 


\section{VI - NASCENTES PÚBLICAS E PARTICULARES}

O Código de Águas, ao enumerar no artigo segundo quais são as águas públicas de uso comum, inclui as nascentes quando forem de tal modo consideráveis que, por si sós, constituam o caput fluminis; (1) bem como as fontes e reservatórios públicos.

E no artigo $8 .^{\circ}$ caracteriza como particulares as nascentes e tôdas as águas situadas em terrenos que também o sejam, quando as mesmas não estiverem classificadas entre as águas comuns.

Resulta disso que as nascentes situadas em terrenos públicos, embora não constituam caput fluminis, são também públicas, desde que tais terrenos sejam do domínio patrimonial, especial ou comum, do Município, do Estado ou da União.

Temos pois a considerar as nascentes como públicas em dois grupos: a) as que constituam caput fluminis; $b$ ) as que se situam em terrenos públicos, embora não sejam caput fluminis.

Quantơ às fontes ou reservatórios, são particulares quando se encontrem em terrenos dessa natureza, mas ainda assim suscetíveis de serem considerados públicos, desde que dêles se abasteça uma população, (2) como veremos mais adiante.

As fontes e reservatórios públicos podem ser de águas de uso comum, como podem ser destinados a uso especial, sem perder o seu caráter de públicas.

\section{VII - REGIME DAS NASCENTES ARTIFICIAIS}

Já vimos que as nascentes podem emergir ao solo, por força exclusiva dos fenômenos da natureza, sem que para isso tenha havido trabalho deliberado do homem, tomandơ neste caso a denominação legítima de "nascentes".

Se, entretanto, elas são consequientes de trabalho do homem para a vinda das águas à superfície, dá-se o que o Código de Águas chama de "indústria humana", passando a ser "nascentes artificiais" em contraposição às "nascentes naturais".

Nessa hipótese é que, como foi dito, recebem mais comumente a denominação de "fontes", especialmente quando há ostensiva apresentação do desemboco das águas.

Os efeitos jurídicos relativos à descarga das águas emergentes em relação aos prédios inferiores, num e noutro casos, são diversos e correspondem àquela ratio juris, que presidia o fenômeno das águas no direito romano.

Se êsses prédios inferiores se subordinam à regra dominante no escoa-mento das águas, tratando-se de nascentes naturais, já não acontece o mesmo com as águas vindas à tona por indústria do homem.

Nesse último caso, fôrça é considerar o interêsse que surge para o beneficiário da fonte em contraste com a molestação, que terão de sofrer os prédios inferiores em face das descargas de águas supérfluas. 
Todavia, no choque dêsses interêsses, tem-se muitas vêzes em consideração o fato de ser a água um bem inestimável, que não pode ser anuladơ pela comodidade secundária.

Por isso, o legislador estabeleceu em certos casos a obrigação de receberem os prédios inferiores tais águas, mediante as normas da servidão legal de escoamento para águas sobejas, também chamadas "superabundantes" ou "superfluas".

Não quis, entretanto, que êsse direito conferido ao dono da fonte ficasse sem o correspectivo de uma obrigação para o paciente da servidão de escoamento; e em favor dêle estabeleceu o direito de ser indenizado dos prejuízos e molestações que sofrer.

Se ao invés de causarem prejuízor e molestações essas águas obtidas artificialmente e descarregadas como sobejas vêm trazer benefício aos prédios inferiores, que, ao contrário de se depreciarem, adquirem maior valor, os benefícios auferidos com essas águas, pelos prédios inferiores, serão então apreciados para consideração do seu valor em face da paciência sofrida, fazendo-se então virtual encontro de contas entre êles e os vexames causados pela água.

Êsse, o sentido racional e legal consubstanciado no art. 92 e seu $\S$ único do Código de Águas. (1)

\section{VIII - LIMITAÇÃo LEgAL À PROPRIEDADE DAS NASCENTES}

O artigo 94 do Código de Águas assim se expressa: "O proprietário de uma nascente não pode desviar-1he o curso, quando da mesma se abasteça uma população".

Êsse artigo tem como fonte imediata o artigo 120 do Projeto VALADÃo.

Melhor parece, entretantơ, a seguinte redação, que, na Câmara dos Deputados, obteve o artigo correspondente do Código de Águas posteriormente em elaboração: "O proprietário de uma nascente não pode desviar o curso das águas quando da mesma se abasteça uma população". (1)

Em realidade, não se modifica o curso da nascente, mas sim o curso das águas, o que permite preferência pela forma parlamentar dơ artigo.

E' essa uma disposição que, encontrando fundamento naquele princípio de solidariedade social, de que nos fala CLóvis, ou de caridade social, na expressão de Romagnosi, merecia acolhimento no velho direito civil como primícia da tendência socializadora atual no assunto das águas, figurando já então como uma das poucas derrogações ao cânon reconhecido da livre disposição do senhor do solo sôbre as nascentes, que nêle emergiam.

$\mathrm{Na}$ Itália - para onde reivindica o insigne LoMonACo a glória dos mais perfeitos regulamentos em tôrno à matéria das águas, e o primado das melhores obras publicadas a respeito, (2) ressaltando aquelas de PECCHIO, (3) Romagnosi, (4) DionisotTi (5) e GiovanetTi (6) - a exceção estava já consignada no artigo 542 do Código Civil, (7) que é constante de matéria idêntica à do artigo 643 do Código Civil da França. (8)

BAUDRY - LACANTINERIE - e WHAL, em admirável precisão de linguagem, assim explicam o fundamento dessa derrogação: "Aqui, como em outros 
casos, o legislador faz prevalecer um interêsse coletivo sôbre o interêsse individual; êle sacrifica o direito do proprietário da nascente pelo da comunhão de habitantes. E é de se notar que o proprietário da nascente se verá privado do seu direito de disposição, sem que se precise proceder contra êle à expropriação por causa de utilidade pública. E' essa uma derrogação grave do direito comum. E explica-se com a urgência das necessidades às quais convém satisfazer. A água é um elemento essencial à vida como o ar".

\section{IX — COMPREENSÃO DO GRAVAME}

Temos na espécie um caso de servidão legal, ou melhor, de serventia legal, que deverá ficar sujeita a interpretação restritiva, como exceção que é ao direito comum.

Pela singeleza, com que está concebido o texto, a derrogação importa sòmente em não poder o proprietáriơ da nascente desviar o curso das águas.

A expressão "curso das águas" sugere, desde logo, a compreensão, de que se não incluíram no intuito do legislador as águas denominadas mortas, como sejam as contidas numa cisterna. num poço, num tanque, num fôsso ou em qualquer reservatório; e, segundo alguns estendendo essa compreensão, a tôdas as águas, que não chegam a transpor os limites do prédio, onde têm nascimento.

Só em relação às águas chamadas vivas tem vibração essa servidão legal, sendo água viva, no entender de PACIFICI - MAzzoni, "aquela que escorre perenemente", embora sujeita a eventual intermitência em razão da sêca. (1)

$\mathrm{E}^{\prime}$ hoje communis opinio que a restrição se verifica não sòmente contra o proprietário do prédio onde as águas vêm à superfície, mas também contra os proprietários daqueles fundos atravessados por elas antes de atingirem 0 local onde sirvam à população, pois que tais prédios não podem ter mais direito que o proprietário da nascente.

Para que se verifique a hipótese em estudo, requer a lei que das águas se abasteça uma população.

Antes de outra análise, é preciso verificar o que pretendeu o legislador incluir no verbo "abastecer".

No sentido etimológico, "abastecer" significa "fartar-se a bastar"; no sentido vulgar, o conceito já se deforma, e passa o vocábula a expressar a idéia menos ampla de "servir para consumo".

Não obstante nossa lei não distinguir entre necessidade e utilidade, como fazem as leis francesa e italiana, os precedentes históricos do dispositivo ou sejam as suas fontes - indicam que o legislador teve em mira mais o sentido vulgar, que o etimológico.

Realmente, em França, a regra correspondente concede aos beneficiários l'eau qui leur est nécessaire, o que se repete na Itália com as expressões l'acqua che é loro necessaria.

Quais os limites da necessidade?

Tem-se entendido e pode-se mesmo afirmar sem discrepâncias, que a liberalidade legal se refere às necessidades domésticas, não se aplicando aos misteres da agricultura e da indústria. (2) 
Foi essa uma doutrina que se expandiu lançada por PARDESSUS, do campo do direito francês para o italiano, e cada vez mais acentua o seu vultơ.

Incluem-se entre necessidades domésticas o beber, o lavar, o dessedentar os animais de uso pessoal e também os bois de arado (3) e ainda, segundo outros, o moer, (4) faculdade essa que tem sido aliás repelida.

A necessidade é elemento para a integração da hipótese, de forma que, se o caso fôr simplesmente de utilidade, já não aproveita aos que dêle queiram fazer incidência na derrogação legal em estudo.

Outrossim, tem-se entendido, na interpretação das fontes do artigo em aprêço, que se a nascente fornece água em quantidade excedente à necessidade da população, que dela se supre, pode o seu proprietário desviar tal excedente para a própria utilidade e confôrto. (5)

Parece que dentro dêsse espírito deve ser entendido o dispositivo legal derrogatório.

Dada a possível elasticidade de interpretação do que seja "necessidade", tudo indica que o legislador pátrio se orientou por aquela decisão da Côrte de Orléans, a que se referem os civilistas estudiosos do assunto, no sentido de admitir o desvio pelo proprietário, desde que os componentes da população tenham à sua disposição, e em quantidade suficiente, outras águas, além daquelas de sua nascente, cujo uso reclamaram, mas em condições menos cômodas.

$$
\mathrm{X} \text { - CHAVES DAS REMisSõES DO TEXTO }
$$

(1) Código Civil Português, art. 444.

(2) Alves Moreira, Das águas no Direito Civil Português, pág. 160.

(3) Dionísio DA GAMA, Das águas no Direito Civil Brasileiro, n. ${ }^{\circ} 34$.

(4) Código Civil, art. 565: "D proprietário de fonte não captada, satisfeitas as necessidades de seu consumo, não pode impedir o curso natural das águas pelos prédios inferiores." Como se vê, a expressão "não captadas" faz referência a águas que fluem naturalmente, o que mais se aplica ao conceito específico das "nascentes".

(5) Sá Pereira, Man. do Cod. Civ., vol. VIII, n. ${ }^{\circ}$ 94; João Luis Alves, Cod. Civ. anotado, comentário ao artigo 565; Carvalho Santos, Cod. Civ. Bras. Interp. vol. VIII, obs. ao art. 565 .

(6) Ver o respectivo texto integral em LoBÃo, Trat. prát. e compendiário das águas, § 76: "Cuja declaração sou servido fazer com a equiidade de que os donos das referidas nascentes etc.". etc.".

(7) Cons. das Leis Civ., art. 901: "mas os donos das nascentes depois de usarem

(8) E' o que Valadão (Direito das Águas, pág. 280) assinala, servindo-se de texto, no mesmo sentido, de Dias Ferreira (Cod. Civ. Com., vol. I, pág. 423): "Na linguagem ordinária e no uso comum, as palavras "fonte" e "nascente" não significam o mesmo pensamento, porque a fonte pressupõe algum trabalho para o aproveitamento das águas; e nas nascentes a água brota naturalmente do solo."

(9) Veloso de Ar.meida, Comº à Lei de Águas, n. ${ }^{\circ} 141$.

(10) Man. du Code Civ. Suisse, n. ${ }^{\circ} 1.314$.

(11) LOBÃo, op. cit., \& 52 .

(12) CaRvalho de MEndonça (M.I.), Rios e Águas Correntes, n. ${ }^{\circ} 2$.

\section{II}

(1) Valadão (Alfredo), op. cit., pág. 280.

(2) Em Enc Giuridica Ital., de MANCINI, vol. I, pág. 969. 
(3) Idem, idem.

(4) Themistocles Cavalcanti, em Introdução a "Rios e Águas Correntes", de C. MENDONÇA, pág. LXXXV: "são correntes, rios, ribeirão, riachos, córrego, arroio, sanga etc.".

(5) De fato no dispositivo se diz: "e ainda que o transponham, quando elas não tenham sido abandonadas, pelo proprietário do mesmo" (prédio particular).

\section{III}

(1) Marchi, in Diz. del Dir. Privato de Scialoja, vol. I, voce "acque".

(2) Idem, op. e loc. cits., letras $f$, g e $h$.

(3) CaRvallo de Mendonça, op. cit., n. ${ }^{\circ} 2$.

(4) VALADÃo, op. cit., págs $279 / 80$

(1) Carvalho de Mendonça, op. cit., n. ${ }^{\circ}$. O insigne mestre faz nesse ponto um prendado estudo acêrca da origem das nascentes.

(2) Art. 95.

(3) Art. 98.

(1) LoBÃo, op. cit., \$ 55 : “A água que nasce em algum prédio é reputada como um dos seus frutos naturais; e porisso pertence por direito ao dono do mesmo prédio e faz parte dele".

(2) Dir. Civ., vol. IV, liv. II, tit. VI, $\$ 31$, n. $^{\circ} 11$.

(3) Digesto Port., pág. 122, n. ${ }^{\circ} 774$.

(4) Artigo 898 .

(5) LAFAyetTe, Direito das Coisas, vol, I, \& $124 \mathrm{n} .^{\circ} 1$.

(6) VAladÃo, op. cit., pág. 286.

(7) Colin et Capitant, Cours élém. de Droit Civ. Fran., vol. I, pág. 731, 5. a ed. Portio agri videtur aqua viva; aqua quae in meo fundo oritur vel illum ingreditur; mea est.

(8) Art. 99 da Lei pcrtuguêsa de águas, de 1919 - Veloso dE AlMEIDA, op. sit.. n. ${ }^{\circ} 141$ e segs.

(9) Marchi, op. e loc. cits.; Dionisottri, Serv. delle acque, n. ${ }^{\circ} 40$; Gianzana, Teorica delle acque privatc, n. ${ }^{\circ} 699$; RICcI, Trat. de Dir. Civ., vol. II, pág. 48, onde assim se expressa: "Una sorgente ad esempio, sgorga nel mio fondo indi seguendo il suo corso naturale, va unirsi ad un demaniale. Dovrà ritenerse demaniale pur essa? No, perchè l'aqua che corre non può ne deve confondersi colla sorgente da cui deriva"; MARCHI, op. e loc. cits.

(10) Code Civ. Fr., art. 641: "Celui qui a une source dans son fond peut en user à sa volonté." (Colin et CAPITANT, op. e loc. cits.).

(11) Spota, Trat. de Der. de Agutas, vol. II, n. ${ }^{\circ} 799$; Cod. Civ. Argentino, artigo 2.637; Cod. espanhol, art. 408 , inc. $10^{\circ}-\mathrm{O}$ mesmo é reconhecido nos direitos inglês e norte-americano, como decorrência das disposições relativas às perålatings waters (águas subterrâneas) e underground springs (fontes).

\section{VI}

(1) Diz-se caput fluminis em relação à fonte onde tem nascimento o rio. PECCHIo definia: Caput fluminis est unde fluminis origen capit. Não é de ser confundido o seu conceito com o que os romanos denominavam caput aquae, isto é, o ponto onde se praticava uma derivação de água.

(2) Art. 94 do Código de Águas.

\section{VII}

(1) "Nessa indenização, porém, será considerado o vaior de qualquer benefício que os mesmos prédios possam auferir de tais águas."

\section{VIII}

(1) Projetos $\mathrm{n}^{\text {0\$ }}$. 457-A, de 1936, e 232, de 1937, art. 79.

(2) Lomonaco, Ist. di Dir. Civ. Ital, vol. III, pág. 379.

(3) De aquaeductu.

(4) Della ragione civile delle acque; Della condotta delle acque. 
(5) Servitù delle acque.

(6) Du régime des eaux.

(7) "Il proprietario della sorgente non può deviarne il corso quando la medesima somministra agli abitanti di un commune o di una frazione di esso l'acqua che è loro necessaria."

(8) "Ne peut pas non plus en user de manière à enlever aux habitants d'une commune, village ou hameau, l'eau qui leur eșt nécessaire."

(9) Baudry - Lacantinerie e Whal, Trat. de Dir. Civ., trad.ital, ed. Vallardi, vol. Dei beni, n. ${ }^{\circ} 849$.

\section{IX}

(1) PaCifici - Mazzoni, Dir. Civ. Italiano, vol. III, parte $2 .^{\mathrm{a}}, \mathrm{n} .^{\circ} 236$. - CARVALHo de MENDONÇA, op. cit., n. ${ }^{\circ} 2$, pág. 19.

(2) LOMONACO, op. e vol. cits., pág. 272.

(3) Demolombe, Cours de Code Napoleon, vol. XI, n. ${ }^{\circ} 95$; AUbrY et RAU, Cours de Dir. Civil, vol. III, \$ 244; Laurent, Principes de Droit Civ., vol. VII, n. 213.

(4) PACIFICI - MAZzonI, op. a vols. cits., n. ${ }^{\circ} 238$.

(5) Lomonaco, in "Enc. Gitrídica", de MANCINI, voce "acque", pág. 557.

\section{SUMMARY}

1. The expressions "source" and "fountain" employed interchangeably both in the Brazilian and in the Portuguese law. In the Brazilian Civil Code (art. 565) "fountain" is the only term used while the term "source" is adopted by the Code of Waters to denote the same concept.

2. The distinction between "source" and "fountain", made by law in the 18th century, is clearly made by Teixeira de Freitas. Yet the Code of Waters considers the two as expressions of an identical concept.

3. The etymological distinction between "source" and "fountain" analyzed. Definitions of "source" according to the Swiss Code. The opinions of several authors on the distinction between "source" and "fountain".

4. The implicit distinction between "source" and fountain" in the Code of Waters, the former being of more general scope. "Sources" are waters that emerge naturally or through human industry; "fountains" presuppose some sort work aiming at the utilization of waters. The opinions of Varcasia, Columela and Themistocles Cavalcanti.

5. Sources, in their general meaning, classifield as "natural" and "artificial". The latter are subdivided into "open" ant closed".

6. The distinction betwwen "source" and "stream". The opinions of Carvalho de Mendonça and Valladares.

7. Origin and determination of sources; the varied processes of their formation.

8. Ownership of sources according to the old Portuguese law and to the Brazilian law. The general principle that ownership of the land where sources are located carries in itself the ownership of them.

9. "Public" and "private" cources according to the Code of Waters. Public sources divided into two classes: (1) those which are caput fluminis and (2) those which are located in public lands, although not being caput fluminis.

10. "Artificial" sources contrasted with "natural" sources. Juridical consequences of the discharge of waters, analyzed. The event of "super-abundant" of "superfluous" waters: its regulation by law, viz. prohibition of deviation of water courses.

11. Legal restrictions to the ownership of sources established by the Code of Waters, imposed by the principle of socia! solidarity. Italian and French jurists quoted on the matter. The distinction between "live" and dead" waters. The criteria of necessity and utility en as bases to the above-mentioned legal restrictions, minutely discussed. 